\title{
A Physical-Cognitive Intervention to Enhance Gait Speed in Older Mexican Adults
}

Bertha Cecilia Salazar-González, PhD; Juana Edith Cruz-Quevedo, DCE; Esther C. Gallegos-Cabriales, PhD;

Maria de los Angeles Villarreal-Reyna, DCE; Oswaldo Ceballos-Gurrola, DSc; Perla Lizeth Hernández-Cortés, MCE;

Maria Eugenia Garza-Elizondo, MC; Marco Vinicio Gómez-Meza, PhD; María Cristina Enriquez-Reyna, MCE

Abstract

Purpose. To test the effects of a physical-cognitive exercise intervention on gait parameters under dualtask conditions in community-dwelling older adults.

Design. A repeated-measures quasi-experimental design, with control and exercise groups, was used.

Setting. Study participants consist of a convenience sample recruited from senior citizens' centers in Monterrey, Mexico.

Subjects. A total of 143 sedentary participants ages 65 to 92 years per group participated.

Intervention. A combined 45- to 60-minute program of physical and cognitive exercises was conducted in three weekly sessions during 12 weeks for the exercise group.

Measures. The spatial gait parameters of speed $(\mathrm{cm} / \mathrm{s})$, step width, and stride length (cm); and the temporal parameters of single and double support time, cadence (steps per minute), and swing time (s) were measured using the GaitRite. Counting backwards or naming animals represented cognitive performance.

Analysis. Two (groups: exercise group vs. control group) by three (time: baseline, week 6, and week 12) repeated-measures multivariate analysis of variance (MANOVA) was applied.

Results. Repeated-measures multivariate analysis of variance revealed a significant group effect (Wilks lambda $\left.F_{4,279}=6.78, p<.001\right)$; univariate analysis showed significant differences for gait speed $(\mathrm{m} / \mathrm{s})$, stride length, cadence, step width, and double support time. Time-by-group interaction showed significance in gait speed and stride length.

Conclusion. The exercise group participants showed increased gait speed, cadence, and stride length, and reduced their step width and time spent with both feet on the ground. Walking while simultaneously performing a cognitive task might prepare older adults for competing/interfering demands from their environments. The protective health benefits of this intervention remain to be investigated. (Am J Health Promot 0000;00[0]:000-000.)

Key Words: Elderly, Gait, Dual-Task, Intervention, Prevention Research. Manuscript format: research; Research purpose: intervention testing; Study design: quasi-experimental; Outcome measure: cognitive and behavioral; Setting: community senior citizen centers; Health focus: physical activity; Strategy: skillbuilding/behavior change; Target population age: seniors; Target population circumstances: low-educated, low socioeconomic status, Monterrey's metropolitan area, and Mexicans

\section{PURPOSE}

With the population's rapid aging and its economic and health care consequences, the maintenance of functional ability in older adults is an important issue of interest because of the dependence usually associated with old age. According to the National Population Council of Mexico (CONAPO), as cited by Ham-Chande (2011), ${ }^{1} 15.5 \%$ of the aged population present some kind of limitation, and of that percent 6 of 10 people have a mobility limitation specifically related to walking, and this number increases with advancing age.

Lack of independence is one of the factors that older adults consider to be responsible for the deterioration of their welfare ${ }^{2}$; to them, being dependent symbolizes feeling like a burden within the family structure. For older adults, the consequences of dependency not only result in functional impairment, but also affect their psychological and social well-being. Functional alterations, particularly in the gait of older adults, have been shown to predict mortality, functional decline,

Bertha Cecilia Salazar-González, PhD; Esther C. Gallegos-Cabriales, PhD; Perla Lizeth Hernández-Cortés, MCE; Maria Eugenia GarzaElizondo, MC; and María Cristina Enriquez-Reyna, MCE, are with the Facultad de Enfermeria, Universidad Autónoma de Nuevo León, Monterrey, Mexico. Juana Edith Cruz-Quevedo, DCE, is with the School of Nursing, University of Veracruz, Veracruz, Mexico. Maria de los Angeles Villarreal-Reyna, DCE, is with the Escuela de Lic. en Enfermería, Universidad Autónoma de Coahuila, Saltillo, Mexico. Oswaldo Ceballos-Gurrola, DSc, is with the Facultad de Organización Deportiva, Universidad Autónoma de Nuevo León, Monterrey, Mexico. Marco Vinicio Gómez-Meza, PhD, is with the School of Economics, Universidad Autónoma de Nuevo León, Monterrey, Mexico.

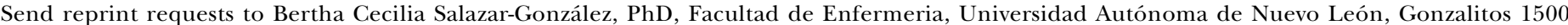
Nte. C.P. 64460, Monterrey, México; bceci195@hotmail.com.

This manuscript was submitted June 25, 2013; revisions were requested October 21, 2013 and February 17, 2014; the manuscript was accepted for publication April 16, 2014. 
and the use of health care services because of falls. ${ }^{3}$ Walking speed is associated with longevity. People with speeds less than $1 \mathrm{~m} / \mathrm{s}$ are at risk for adverse events. ${ }^{4,5}$

Walking was previously considered an automated activity; now it is known that walking requires attention, orientation, and memory. Walking in the streets presupposes knowing where one is headed, and this in turn implies remembering how to get to the intended place. In a way, this represents a dual task (walking and being aware of directions).

Walking in public imposes extra attentional demands on older adults because the risk of falling is greater when they face obstacles, noises, signs, or talking while walking (dual task), and thus their attention is divided. ${ }^{6-8}$ But as people age, attentional resources become limited and may diminish older people's ability to do two things at a time. ${ }^{9}$ Scholars such as LundinOlsson et al. ${ }^{10}$ were among the first to detect the risk of falls in older adults who stopped walking when talking. Since then, interest in the performance of older adults in dual-task conditions has increased. According to YogevSeligmann et al., ${ }^{11}$ dual tasks create a conflict; attention is divided and the brain needs to prioritize between the performance on gait and the secondary task. Additionally, older adults may take more time to complete their gait task or the secondary task. ${ }^{12}$ Physical cognitive interventions are important to train older adults in dual tasks and improve their skills while walking in the real world, as Lord and Rochester ${ }^{13}$ suggest.

Intervention studies on improvements of gait parameters while doing an additional task (dual task) are scarce. Interventions have focused either on physical exercises or cognitive training. Also, dual-task studies may involve walking while performing a motor task or while performing a cognitive task. Yang et al. ${ }^{14}$ focused on the effects of a physical exercise intervention using a dual motor task in Chinese adults who had suffered a stroke. You et al. ${ }^{15}$ developed a cognitive-gait intervention to measure dualtask effects. The intervention in this study involved both physical and cognitive training.
Previous intervention studies used small sample sizes, and even though they do not report the participants' years of schooling, given the scores in the Mini Mental State Examination test (MMSE) it may be assumed they had more years of schooling than participants in this study. We wanted to know if participants with few years of schooling could also improve their walking abilities in a dual-task condition; participants were not excluded based on scores of the MMSE or years of schooling.

The purpose of this study was to test the effects of a combined physicalcognitive exercise intervention on walking speed, step width, stride length, double support time, swing, and cadence during a cognitive dual task (walking while counting backwards or naming animals) in older adults in the metropolitan area of Monterrey.

\section{METHODS}

\section{Design}

A quasi-experimental design with repeated measures and with control and exercise groups was used. ${ }^{16}$ It was expected that participants in the exercise group would have better physical and cognitive performance while doing a dual-task activity. The intervention consisted of a program of physical exercise combined with cognitive exercises offered in three weekly sessions of 45 to 60 minutes for 12 weeks. The control group underwent only measurements, and they received a brochure on fall prevention. The measurements were performed before the first session (baseline), and at the end of weeks 6 and 12 .

The participants were selected from senior citizen centers managed by the Mexican National System for Integral Family Development (DIF) in the metropolitan area of Monterrey, Mexico. Convenience sampling was conducted through direct invitation to participate in the study.

\section{Sample}

The sample size was determined using the statistical package ${ }^{17}$ nQuery Advisor 2.0 for a repeated-measures model with four levels, $95 \%$ confidence, a power for group-by-time interaction of $92 \%$, and a small effect size (.35). The sample size obtained was 141 participants for each group; estimating a $30 \%$ rate of attrition, the sample size was increased to 188 participants per group. ${ }^{18,19}$

Adults 65 years or older who ambulated without dragging their feet and were sedentary (score <9.4) according to the physical activity questionnaire for older adults were included. ${ }^{20}$ Older adults had to raise each foot from the floor to give each step, in order to mark the footfalls on the mat. Older adults who presented medical contraindications to exercise according to the physical activity questionnaire ${ }^{21}$ were excluded. Two participants in the control group who reported having joined an exercise program between the second and third measurements were excluded.

The senior centers were selected based on their sufficient space to safely carry out the exercise sessions, and were easily accessible to the elderly or were at a walking distance.

The study was approved by the ethics committee of the School of Nursing of the Universidad Autónoma de Nuevo León. Informed consent was obtained from each participant. Authorization was obtained from the central organization that runs the senior centers. The study was explained to potential participants in the senior centers. Once they manifested a willingness to participate, inclusion criteria were verified and informed consent was signed by each participant and the primary investigator.

\section{Measures}

Descriptive data included age, gender, education, number of people living with the older adult, chronic diseases, use of benzodiazepines, and number of falls during the past year. Other measurements used were the $\mathrm{MMSE}^{22}$ and the updated version of the Depression Scale from the Center for Epidemiologic Studies (Escala de Depresión del Centro para Estudios Epidemiológicos), with 35 items. ${ }^{23}$ The latter results are not shown.

The MMSE developed by Folstein et al. ${ }^{22}$ is a rapid and the most commonly used test for examination of cognitive mental status examination, and to detect cognitive deficit. The MMSE explores orientation, memory and attention, and the ability to name ob- 
jects, follow verbal and written commands, write a short sentence spontaneously, and copy a complex polygon. This test requires 5 to 10 minutes to administer. The total score is 30 points; for participants older than 60 years the cutoff point of 24 is considered normal cognition. The MMSE's cutoff score has raised some concerns with Mexican older adults with low education with regard to sensitivity and specificity. Ostrosky et al. ${ }^{24}$ suggest different cutoff points according to years of schooling for older adults. Results are presented using that recommendation.

Gait was measured using the GaitRite $5.50 \mathrm{~m} \times 0.90 \mathrm{~m}$ system. This system consists of a mat with electronic sensors, and software that automates measurements of temporal and spatial gait parameters and captures an image of the participant while walking. The values are stored in the software and exported to Excel, and then to SPSS.

The spatial parameters were: speed, width, and stride length. The speed was obtained by dividing the distance by the time of ambulation, and it was recorded in $\mathrm{cm} / \mathrm{s}$. The step width was the perpendicular distance between the heel of one foot and the progression line of the opposite foot. Stride length was measured from the footprint of a heel to the next heel of the same foot, from the right foot heel to the next right heel (complete cycle of one step).

The temporal measurements of gait are double support, swing, and cadence. Double support is the time that both feet are in contact with the ground. Swing time refers to the time of the last contact of the footprint to the first contact of the next footfall of the same foot (airtime). Cadence refers to the number of steps per minute.

Cognitive performance was measured by the number of correct digits (subtracting backwards) starting from a random number below 50 , or animals, and was registered in the gait software simultaneous to the walk across the mat.

\section{Procedure}

All data were collected in the senior centers in a quiet classroom assigned for data collection. Only two research assistants were in the room (to prevent distractions) while performing the gait parameters (one at the computer and another one walking close behind the older adult).

Measurements were done at baseline and at the end of the 6th and 12th weeks. Each participant was instructed to conduct two different tasks. For the first task, he or she was asked to walk at his or her usual pace along the electronic mat, starting $1 \mathrm{~m}$ before and ending $1 \mathrm{~m}$ after the mat (simple task). Each participant made a trail over the mat to verify that he or she understood the instructions. Participants walked across the mat twice, closely followed by a monitor to safeguard their physical safety. There were no contingencies.

For the second task, the participant was asked to walk again on the mat, adding a cognitive task that consisted of counting backwards aloud (dual task) starting from a random number between 20 and 50. If the participant had difficulty counting, names of animals could be listed instead, but if an animal name was repeated, it was marked as an error. The cognitive task performance was obtained by subtracting the number of errors from the number of correct counting or naming animals during the passage over the mat.

\section{INTERVENTION}

The duration of the whole study was 18 months, from June 2010 to December 2012. The treatment consisted of a 12-week cognitive/physical exercise program consisting of three sessions per week. At the beginning of the program the sessions lasted 45 minutes; from week 3 onward they lasted 60 minutes. Each exercise session included the following steps: (1) warmup for 10 minutes; (2) strength training and muscular resistance with .500kg dumbbells and leggings, starting with $227 \mathrm{~g}$ and gradually increasing the weight until the participant could tolerate $680 \mathrm{~g}$, for 20 minutes; (3) the cognitive routine included motor tasks (walking and simultaneously naming days of the week, months, and seasons, both in progressive and reverse order) for 10 minutes; walking in a zigzag pattern repeating sayings; and walking listening to music, passing a ball from one hand to the other, bouncing a ball, and sorting traffic cones and barriers, for 10 minutes; and (4) stretching and relaxation with music for 10 minutes.

The intervention was offered by previously trained facilitators who followed an instruction manual and were assisted by two to four monitors, depending on the number of participants. The participants' blood pressure was measured before, during, and after each session following the guidelines of the American College of Sports Medicine. ${ }^{25}$

\section{ANALYSIS}

Descriptive statistics and the Levene and Mann-Whitney $U$ tests were conducted for baseline differences. Effects of the intervention on gait parameters and number of digits or animals named while walking were examined by two (groups: exercise group vs. control group) by three (time: weeks 0 , 6 , and 12) repeated-measures multivariate analysis of variance (MANOVA).

Figure 1 shows the flowchart of participants. Some of the reasons for withdrawal from the study were change of address, disease, falls in the home, and death of uncertain cause.

\section{RESULTS}

The data correspond to 143 participants per group who underwent the three required measurements (weeks 0,6 , and 12); in the case of the exercise group, results were included for those who attended at least $60 \%$, or 22 of the 36 exercise sessions: A total of 27 participants did not meet this criterion and were excluded from the analysis. The control group participants came from 11 DIF centers, and the exercise group participants came from 9 DIF centers in the metropolitan area of Monterrey.

The average ages of participants in the control and exercise groups were $74 \pm 6.31$ years and $71 \pm 5.74$ years, respectively, with $4 \pm 3.53$ years of schooling and $6 \pm 4.11$ years of schooling for the control and exercise groups, respectively. Most of the participants were women in the control group $(120 ; 84 \%)$ and the exercise group $(116 ; 81 \%)$. Mann-Whitney $U$ 
Figure 1

Flowchart of Enrolled Participants*

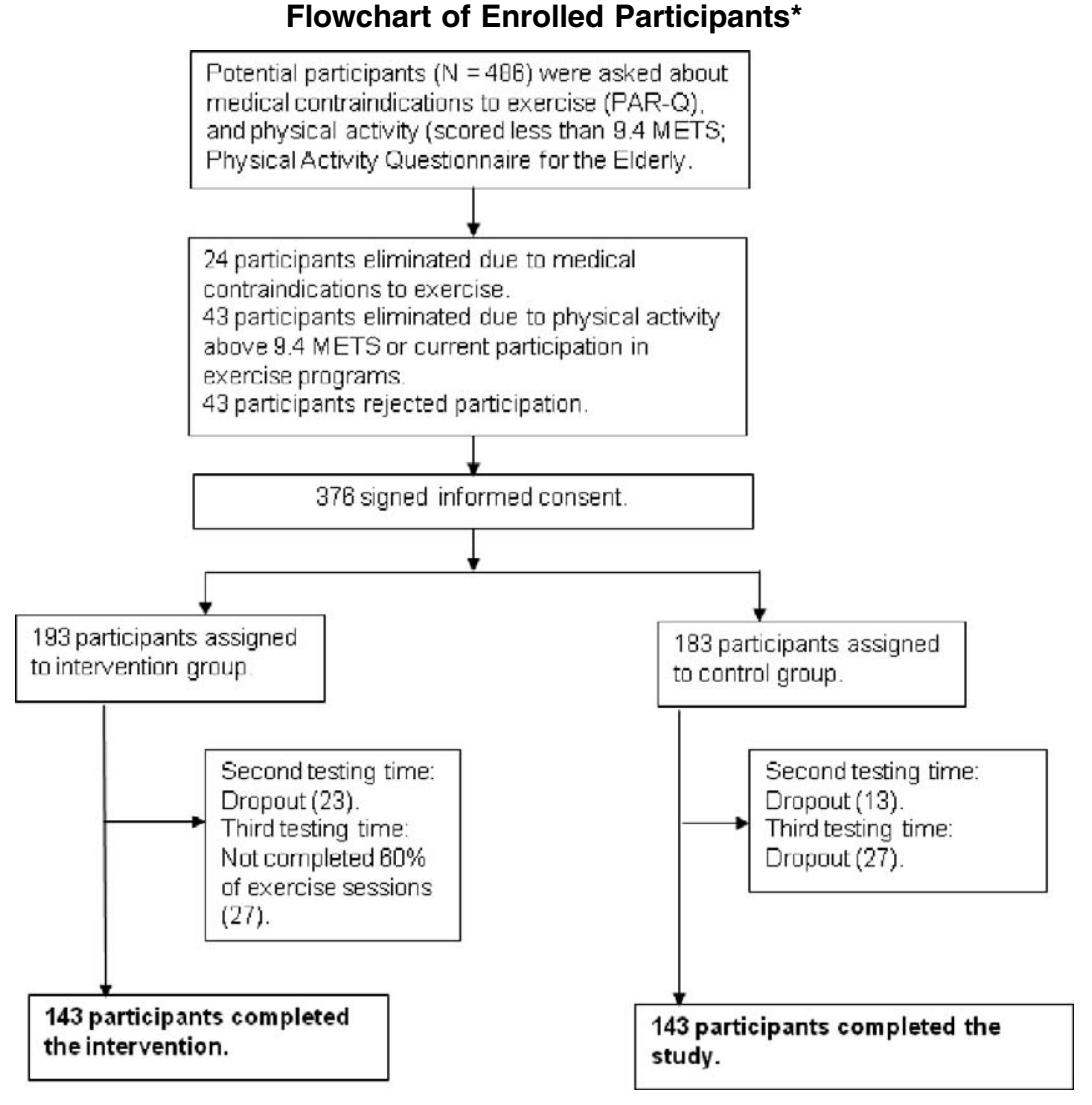

*PAR-Q indicates Physical Activity Readiness Questionnaire; and METS, Metabolic Equivalent of Task.

tests indicated that the control group was significantly older and less educated $(p<.01)$, but Levene tests were not significant $(p=.16$ and .35 , respectively), indicating homogeneity of variance between groups.

At the beginning of the intervention, the average number of digits correctly named during the dual-task walking test was $12.36( \pm 5.63)$ by the control group and $13.58( \pm 5.73)$ by the exercise group; at the end of the intervention it was $13.04( \pm 4.95)$ by the control group and $14.44( \pm 4.79)$ by the exercise group.

The baseline speed at a usual pace for the control group was $\bar{X}=86.28 \pm$ $21.52 \mathrm{~cm} / \mathrm{s}$, with a median of 83.80 $\mathrm{cm} / \mathrm{s}$; for the exercise group, it was $\bar{X}=$ $93.53 \pm 18.26 \mathrm{~cm} / \mathrm{s}$, with a median of $92.20 \mathrm{~cm} / \mathrm{s}$. The baseline width at a usual pace was $\bar{X}=9.14 \pm 3.35$ with a median of 8.81 for the control group, and $\bar{X}=9.20 \pm 3.21$ with a median of
8.86 for the exercise group. Wilcoxon tests showed significant differences between the width at usual gait and dual-task (Table 1) for both groups $(Z$ $=-6.27 ; p=.001)$. According to these means, walking while simultaneously performing a cognitive task (i.e., a dual task), indicates that older adults compensate for their stability by expanding the base of support and slowing down their pace.

Table 1 shows the descriptives of the gait parameters during the dual-task for each group and the Mann-Whitney $U$ test. Except for swing and width, the exercise group obtained measurements that were significantly better than those of the control group. Levene tests for all gait parameters were not significant.

The participants were classified according to their baseline speed at normal gait. To determine the progression of the speed under dual-task conditions, Wilcoxon tests were performed according to the following gait categories: low, $<0.7 \mathrm{~m} / \mathrm{s}$; moderate, 0.7 to $1 \mathrm{~m} / \mathrm{s}$; and fast, $>1 \mathrm{~m} / \mathrm{s}$. Table 2 indicates that the exercise group showed significant improvements between weeks 6 and 12, whereas the control group showed no significant differences.

\section{Repeated-Measures MANOVA}

Repeated-measures MANOVA revealed significant differences between groups (Wilks lambda $\left[F_{4,279}=6.78 ; p<\right.$ $.001])$. Univariate repeated-measures MANOVA showed group differences for gait speed $(\mathrm{m} / \mathrm{s} ; p<.001)$, stride length $(p<.001)$, double support time $(p=.018)$, width step $(p=.026)$, and cadence $(p=.027)$. The number of digits or animals named while walking $(p=.07)$ and swing did not achieve significance $(p=.89$; see Table 3$)$. Within subjects repeated-measures 
MANOVA showed a time effect (Wilks lambda $\left.F_{8,275}=2.31 ; p<.020\right)$, and an interaction effect of time by group $\left(F_{8,275}=2.09 ; p<.025\right)$. But univariate repeated-measures MANOVA revealed interaction effect of time by group only for gait speed $(F=3.33 ; p=.037)$ and stride length $(F=4.36 ; p=.013)$.

The exercise group showed the following mean differences of gait parameters under dual-task conditions from baseline to the end of the study: gait speed $5.65 \mathrm{~cm} / \mathrm{s}$, stride length $4.33 \mathrm{~cm}$, step width $-.69 \mathrm{~cm}$, double support time -.04 , and cadence (steps per minute)

2.6. For mean values, see Table 3 .

The gait speed $(\mathrm{cm} / \mathrm{s})$ and stride length also showed an interaction of time by group. The exercise group's gait speed and stride length increased by the effect of the intervention. The interaction effects are depicted in Figure 2. Marginal means for variables that did not show interaction effects are shown in Table 4.

\section{DISCUSSION}

The average age of the participants in this study is similar to that of other studies where cognitive motor training or purely motor training was performed under dual-task conditions. $^{15,26}$

The control and exercise groups showed differences in the variables of age and education, and in most baseline parameters of gait, but groups showed homogeneity of variance. Although the older adults in both of the groups visited DIF centers once a week, the initial differences between the groups may have occurred because the participants in the exercise group were affiliated with DIF centers that have more space and personnel resources and that develop various activities that keep seniors more active. Appropriate space was required to develop the intervention. Repeated-measures MANOVA was used to explore differences between groups for three measurement points: baseline, week 6 , and week 12.

The results suggest that the exercise participants showed changes over time in important gait parameters. Participants in the exercise group improved their speed in $\mathrm{cm} / \mathrm{s}$, took longer steps,
Table 1

Description of the Mini Mental State Examination Test (MMSE) and Baseline Characteristics of Gait Under Dual-Task Conditions by Group and Mann-Whitney $U$ Test

\begin{tabular}{|c|c|c|c|c|c|c|c|c|}
\hline \multirow[b]{2}{*}{ Group } & \multicolumn{3}{|c|}{ Control $(n=183)$} & \multicolumn{3}{|c|}{ Exercise $(n=193)$} & \multicolumn{2}{|c|}{ Mann-Whitney $U$ Test } \\
\hline & Mean & SD & Median & Mean & SD & Median & $\boldsymbol{U}$ & $p$ \\
\hline \multicolumn{9}{|c|}{ MMSE by years of schooling } \\
\hline 0 & 20.05 & 5.18 & 20.00 & 21.15 & 5.33 & 22.00 & & \\
\hline $1-4$ & 23.11 & 3.80 & 24.00 & 24.89 & 4.01 & 27.00 & & \\
\hline $5-9$ & 25.29 & 4.19 & 26.00 & 26.34 & 2.75 & 27.00 & & \\
\hline 10 or more & 27.10 & 2.42 & 28.00 & 28.32 & 1.49 & 29.00 & & \\
\hline Speed, cm/s & 67.38 & 22.44 & 65.80 & 79.13 & 21.41 & 77.50 & $12,130.5$ & 0.001 \\
\hline Width, cm & 10.16 & 3.52 & 10.22 & 9.66 & 3.51 & 9.45 & $15,776.5$ & 0.074 \\
\hline Stride length, cm & 92.52 & 20.04 & 92.27 & 102.65 & 18.68 & 102.97 & 1205.5 & 0.001 \\
\hline Double support, s & 0.56 & 0.25 & 0.49 & 0.48 & 0.29 & 0.44 & $13,407.5$ & 0.001 \\
\hline Swing, s & 0.44 & 0.08 & 0.42 & 0.43 & 0.10 & 0.42 & $15,883.0$ & 0.092 \\
\hline \multicolumn{9}{|l|}{ Cadence, steps } \\
\hline$\times \min$ & 86.25 & 15.95 & 87.40 & 92.18 & 14.91 & 91.70 & $13,781.0$ & 0.001 \\
\hline
\end{tabular}

increased the steps per minute, and decreased the amplitude and the seconds when both feet were supported at the same time on the ground, while simultaneously performing a cognitive task. The interaction of time by group for gait speed and stride length suggests that the intervention was effective for those parameters.
Balance is an important variable in older adults, but in this study it was not measured directly. The participants in the exercise group reduced their step width and time spent with both feet on the floor, suggesting they had better balance.

Generally, intervention studies involving cognitive training, motor

\begin{tabular}{|c|c|c|c|c|}
\hline \multicolumn{5}{|c|}{$\begin{array}{c}\text { Table } 2 \\
\text { Wilcoxon Test for Gait Speed (cm/s) Changes Under Dual-Task Conditions } \\
\text { by Baseline Gait Speed Group }\end{array}$} \\
\hline Group & Mean \pm SD & Median & $Z$ & $p$ \\
\hline \multicolumn{5}{|l|}{ Control } \\
\hline Gait $<0.7 \mathrm{~m}\left(\mathrm{n}=31^{\star}\right)$ & & & -0.862 & 0.398 \\
\hline Week 6 & $51.06( \pm 14.85)$ & 51.60 & & \\
\hline Week 12 & $52.53( \pm 16.31)$ & 48.80 & & \\
\hline Gait $0.7-1 \mathrm{~m}(\mathrm{n}=82)^{*}$ & & & -0.878 & 0.380 \\
\hline Week 6 & $69.20( \pm 16.24)$ & 69.52 & & \\
\hline Week 12 & $70.04( \pm 16.27)$ & 69.50 & & \\
\hline Gait $>1 m\left(n=30^{\star}\right)$ & & & -0.504 & 0.314 \\
\hline Week 6 & $80.99( \pm 20.12)$ & 82.57 & & \\
\hline Week 12 & $83.45( \pm 17.80)$ & 85.25 & & \\
\hline \multicolumn{5}{|l|}{ Exercise } \\
\hline Gait $<0.7 \mathrm{~m}\left(\mathrm{n}=13^{\star}\right)$ & & & -2.411 & 0.016 \\
\hline Week 6 & $55.45( \pm 16.42)$ & 58.05 & & \\
\hline Week 12 & $62.00( \pm 17.99)$ & 58.30 & & \\
\hline Gait $0.7-1 \mathrm{~m}\left(\mathrm{n}=80^{\star}\right)$ & & & -2.764 & 0.006 \\
\hline Week 6 & $76.22( \pm 17.95)$ & 77.00 & & \\
\hline Week 12 & $79.63( \pm 14.32)$ & 79.00 & & \\
\hline Gait $>1 \mathrm{~m}\left(\mathrm{n}=50^{\star}\right)$ & & & -3.591 & 0.001 \\
\hline Week 6 & $95.34( \pm 20.24)$ & 94.75 & & \\
\hline Week 12 & $102.80( \pm 19.47)$ & 102.50 & & \\
\hline
\end{tabular}

* Number of participants by categories of speed at normal baseline gait speed. 
Table 3

Univariate Analysis of Between-Group Comparisons of Outcome Variables

\begin{tabular}{|c|c|c|c|c|c|c|c|}
\hline \multirow[b]{2}{*}{ Measures } & \multicolumn{3}{|c|}{ Control Group } & \multicolumn{3}{|c|}{ Exercise Group } & \multirow{2}{*}{$\underset{p}{\text { Group Effect }}$} \\
\hline & Week 0 & Week 6 & Week 12 & Week 0 & Week 6 & Week 12 & \\
\hline Speed, cm/s & & & & & & & $<0.001$ \\
\hline Mean & 67.07 & 67.92 & 68.3 & 80.94 & 81.2 & 86.59 & \\
\hline SD & 22.18 & 19.45 & 19.08 & 22.45 & 22.1 & 21.12 & \\
\hline Stride length, cm & & & & & & & 0.001 \\
\hline Mean & 92.17 & 92.97 & 93.17 & 105.08 & 105.54 & 109.41 & \\
\hline SD & 18.29 & 16.52 & 17.23 & 18.62 & 17.5 & 17.56 & \\
\hline Width, cm & & & & & & & 0.026 \\
\hline Mean & 10.25 & 10.08 & 10.15 & 9.28 & 8.93 & 8.59 & \\
\hline SD & 3.29 & 3.27 & 3.39 & 3.21 & 3.58 & 3.59 & \\
\hline Double support, s & & & & & & & 0.016 \\
\hline Mean & 0.56 & 0.54 & 0.53 & 0.48 & 0.47 & 0.44 & \\
\hline SD & 0.24 & 0.16 & 0.17 & 0.32 & 0.14 & 0.14 & \\
\hline Swing, s & & & & & & & 0.89 \\
\hline Mean & 0.45 & 0.45 & 0.44 & 0.44 & 0.43 & 0.43 & \\
\hline SD & 0.08 & 0.09 & 0.07 & 0.11 & 0.07 & 0.07 & \\
\hline Cadence, steps $\times$ min & & & & & & & 0.027 \\
\hline Mean & 85.84 & 87.14 & 88.24 & 91.83 & 91.34 & 94.43 & \\
\hline SD & 16.69 & 15.33 & 15.04 & 15.5 & 13.76 & 14.04 & \\
\hline Digits/animals & & & & & & & 0.076 \\
\hline Mean & 12.36 & 12.06 & 13.04 & 13.58 & 14.32 & 14.44 & \\
\hline SD & 5.63 & 4.5 & 4.95 & 5.73 & 5.38 & 4.79 & \\
\hline
\end{tabular}

training, or mixed training (dual task) report results of habitual or normal gait speed. Few studies measure gait parameters under dual-task conditions.

Silsupadol et al. ${ }^{27}$ reported effects similar to those in this study in terms of gait speed. They compared the effects of three interventions on the gait speed of older adults (a simple physical task compared with two dual motorcognitive tasks with different emphases). Unlike our study, gait speed was measured in terms of the time taken to complete $6 \mathrm{~m}$, using a stopwatch. Participants in the dual-task groups significantly improved gait speed dur- ing the dual task compared with the simple-task group. In this study, the difference obtained in the gait speed was lower than the difference reported in Yang et al. ${ }^{14}$ and Silsupadol et al. ${ }^{27}$ These authors note that the minimum changes required to be considered significant in humans have not been established for the dual task.

Dual-task exercises showed improvement of the experimental group in gait speed and stride length compared with their performance at baseline and with the control group. ${ }^{14} \mathrm{~A}$ difference was that gait parameters were measured using a motor dual task (walking and holding a tray with two glasses filled with water) and not a cognitive dual task. It may be easier to focus on a motor task and not on a less common cognitive task.

You et al. ${ }^{15}$ developed a dual-task cognitive-gait intervention. Apparent physical exercises were not included; thus, the exercise group did not improve its fast gait speed but did show significant changes in the memory exercises, in contrast to the control group. The authors noted that when a cognitive task is added to a motor task, attention is divided and speed is affected. This suggests that to improve physical and cognitive performance the intervention should place an equal focus on physical and cognitive training.

Recently a cognitive-motor intervention showed significant improvements

Figure 2

Time-by-Group Interaction: Gait Speed and Stride Length
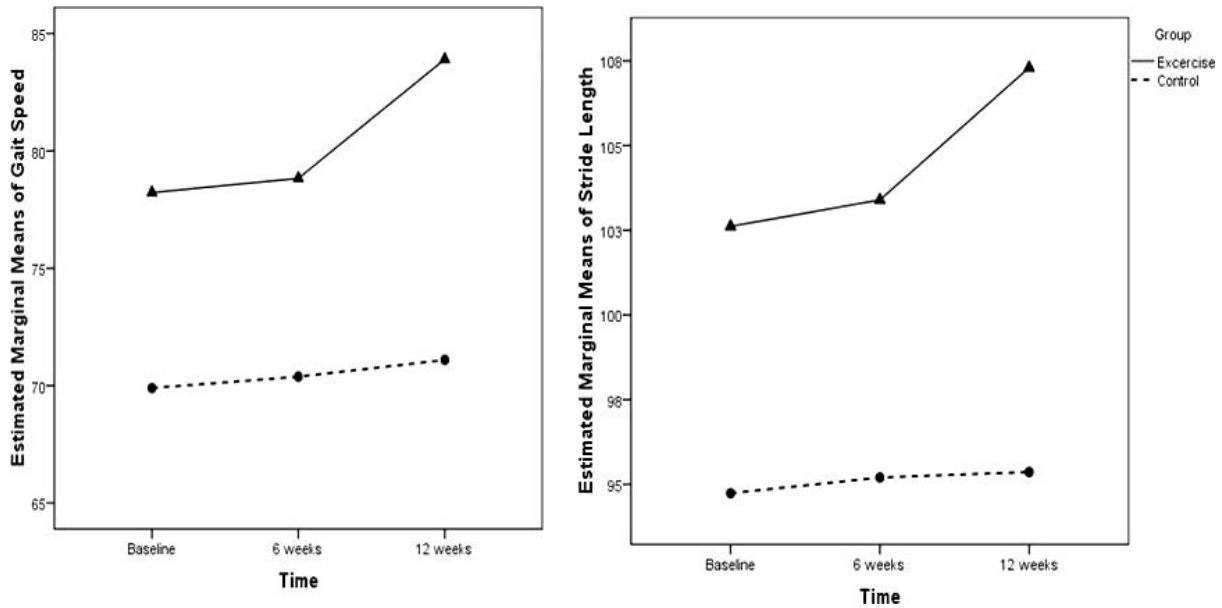
Table 4

Marginal Means of Double-Support Time, Step Width, Swing, Cadence, and Digits or Animals by Group

\begin{tabular}{lcc}
\hline & \multicolumn{2}{c}{ Groups } \\
\cline { 2 - 3 } $\begin{array}{c}\text { Variable and } \\
\text { Measurement }\end{array}$ & $\begin{array}{c}\text { Control, Mean (SD) } \\
(\mathbf{n}=\mathbf{1 4 3})\end{array}$ & $\begin{array}{c}\text { Exercise, Mean (SD) } \\
(\mathbf{n}=\mathbf{1 4 3})\end{array}$ \\
\hline Double-support time & & \\
$\quad$ Week 0 & $0.56(0.24)$ & $0.48(0.35)$ \\
Week 6 & $0.54(0.16)$ & $0.47(0.14)$ \\
Week 12 & $0.53(0.17)$ & $0.44(0.14)$ \\
Step width & $9.28(3.21)$ & $9.28(3.21)$ \\
Week 0 & $10.08(3.27)$ & $8.93(3.58)$ \\
Week 6 & $10.15(3.39)$ & $8.59(3.59)$ \\
Week 12 & & \\
Swing & $0.45(0.11)$ & $0.44(0.11)$ \\
Week 0 & $0.44(0.09)$ & $0.43(0.06)$ \\
Week 6 & $0.43(0.07)$ & $0.43(0.07)$ \\
Week 12 & & \\
Cadence & $85.84(16.69)$ & $91.84(15.50)$ \\
Week 0 & $87.14(15.33)$ & $91.34(13.76)$ \\
Week 6 & $88.24(15.04)$ & $94.43(14.04)$ \\
Week 12 & & \\
Digits/animals & $12.36(5.63)$ & $13.58(5.73)$ \\
Week 0 & $12.06(4.50)$ & $14.32(5.38)$ \\
Week 6 & $13.04(4.95)$ & $14.45(4.79)$ \\
Week 12 & & \\
\end{tabular}

in the gait parameters of the dance group in contrast to the control group. ${ }^{28}$ Although they used an interactive video game (dance) and the authors argued that it may well serve to train cognitive function in older adults, cognitive performance was not measured.

No interaction effect was obtained in digits or animals named while participants walked across the mat. A possible explanation is that the time spent on cognitive exercises was less than the time spent on physical exercises.

The literature suggests that both walking speed and cognitive function are important in preventing falls. Cognitive decline in older adults has been shown to predict loss of mobility. The effect of dementia on gait has been well documented. ${ }^{29}$ According to Allali et al., ${ }^{30}$ basal ganglia and their connections with cortical regions are crucial to both movement initiation and cognitive aspects. They concluded that research evidence supports that cognitive-related gait changes are also associated with the processing of information in cortical regions.

Previous studies have used very small samples (6-13 per group), unlike the current study. Therefore, there may have been greater control of the intervention, because it was applied by one facilitator. An inclusion criterion to enter those studies was the score on the MMSE. In this study, years of education range from 0 to 20 , but half of the participants had 5 or fewer years of schooling. Performance of dual tasks is dependent on cognitive function, and in this study performance of cognitive function showed a great variation. The intervention was able to show effects of gait parameters under a cognitive dual task.

Being able to walk while simultaneously performing a cognitive task (counting or listing names of animals) helps the older adult to walk around difficult environments filled with obstacles or signs, such as those usually found in the public street. This task can be a protective factor for adverse events (i.e., falls, hospitalizations). Older adults and their families need to be encouraged to practice walking, trying to improve their speed in protected environments like parks.

Unfortunately, results cannot be generalized to other populations of older adults because of convenient sampling technique; participants showed relatively low education.

Some of the limitations were that the intervention could undergo variations over time and because of the different facilitators and intervention sites. Not having strict control over the intervention application sites (infrastructure) can adversely affect the behavior of the different groups. However, the results can be reproduced despite the different realities affecting this intervention.

More interventions devoting equal time to both cognitive and physical exercises are needed, and more importantly, follow-up studies are required.

\section{SO WHAT? Implications for Health Promotion Practitioners and Researchers}

What is already known on this topic?

Few studies have used a dual task as an intervention in different population groups. One study focused on gait speed simultaneous to a cognitive task (mathematical operations) and one to a motor task (holding a tray with a glass of water). Exercise interventions ranged from 4 to 6 weeks to improve flexibility and strength. Cognitive exercises consisted of one-digit mathematical operations or memorizing words.

\section{What does this article add?}

Exercise group participants increased gait speed and stride length, and reduced width and time of double support under a cognitive dual-task condition.

What are the implications for health promotion practice or research?

Walking while performing a cognitive task might prepare older adults to negotiate competing demands from their environments. Further exploration is needed to determine protective health benefits and encourage older adults to practice dual tasks.

\section{Acknowledgment}

The study was possible thanks to the funding institution, the Consejo Nacional de Ciencia y Tecnologia (CONACYT), 86801 (SOOO8-FONSEC SSA/IMSS/ISSSTE).

\section{References}

1. Ham-Chande R. Diagnóstico sociodemográfico del envejecimiento en México. In: La situación demográfica de México, 2011. Mexico, DF: CONAPO. 
Available at: http://www.conapo.gob.mx/ es/CONAPO/Diagnostico_socio_ demografico_del_envejecimiento_ en_Mexico. Accessed May 1, 2014.

2. Pelcastre-Villafuerte BE, Márquez-Serrano $\mathrm{M}$. The meaning of aging in older adults from four cities of the country [in Spanish]. In: Salgado VN, Wong R, eds. Envejecimiento, Pobreza y Salud en Población Urbana. Un Estudio en Cuatro Ciudades de México. Cuernavaca, Mexico: Instituto Nacional de Salud Pública; 2006:135-152.

3. Verghese J, LeValley A, Hall CB, et al. Epidemiology of gait disorders in community-residing older adults. $J \mathrm{Am}$ Geriatr Soc. 2006;54:255-261.

4. Cesari M, Kritchevsky SB, Penninx BW, et al. Prognostic value of usual gait speed in well-functioning older people-results from the Health, Aging and Body Composition Study. J Am Geriatr Soc. 2005; 53:1675-1680

5. Studenski S, Perea S, Wallace D, et al. Physical performance measures in the clinical setting. J Am Geriatr Soc. 2003;51: 314-322.

6. Jansen DA, Keller ML. Cognitive function in community-dwelling elderly women. $J$ Gerontol Nurs. 2003;29:34-43.

7. Shumway-Cook A, Patla AE, Stewart A, et al. Environmental demands associated with community mobility in older adults with and without mobility disabilities. Phys Ther. 2002;82:670-681.

8. Hausdorff J, Schweiger A, Herman T, et al. Dual-task decrements in gait: contributing factors among healthy older adults. $J$ Gerontol A Biol Sci Med Sci. 2008;63:13351343.

9. Verghese J, Buschke H, Viola L, et al. Validity of divided attention tasks in predicting falls in older individuals: a preliminary study. J Am Geriatr Soc. 2002; 50:1572-1576.

10. Lundin-Olsson L, Nyberg L. Gustafson Y. "Stops walking when talking" as a predictor of falls in elderly people. Lancet. 1997;349:617.

11. Yogev-Seligmann G, Hausdorff JM, Giladi N. The role of executive function and attention in gait. Mov Disord. 2008;23:329-342.

12. Shumway-Cook A, Brauer S, Woollacott M. Predicting the probability for falls in community-dwelling older adults using the Timed Up \& Go Test. Phys Ther. 2000; 80:896-903.

13. Lord S, Rochester L. Walking in the real world: concepts related to functional gait. J Physiother. 2007;35:126-130.

14. Yang YR, Wang RY, Chen YC, Kao MJ. Dual-task exercise improves walking ability in chronic stroke: a randomized controlled trial. Arch Phys Med Rehabil. 2007;88:1236-1240.

15. You JH, Shetty A, Jones T, et al. Effects of dual-task cognitive-gait intervention on memory and gait dynamics in older adults with a history of falls: a preliminary investigation. NeuroRehabilitation. 2009;24: 193-198.

16. Burns N, Grove SK. The Practice of Nursing Research. Philadelphia, Pa: Saunders Company; 2001.

17. Elashoff JD. nQuery Advisor [computer software]. Version 2.0. Boston, Mass: Statistical Solutions Ltd; 1995.

18. Cruz-Quevedo JE. Ejercicio de Resistencia Muscular en la Funcionalidad Física del Adulto Mayor [dissertation]. Monterrey, Mexico: Universidad Autónoma de Nuevo León; 2006.

19. Salazar-González BC. Responses to exercise in older women [in Spanish]. Ciencia UANL. 2001;4:169-176.

20. Voorrips LE, Ravelli CJ, Dongelmans CA, et al. A physical activity questionnaire for the elderly. Med Sci Sports Exerc. 1991;23: 974-979.

21. Gledhill N. Physical Activity Readiness Questionnaire (PAR-Q) and You. Ontario, Canada: Canadian Society for Exercise Physiology; 2002.
22. Folstein MF, Folstein SE, McHugh T. "Mini-mental state": a practical method for grading the cognitive state of patients for the clinician. J Psychiatr Res. 1975;12: 189-198.

23. Reyes-Ortega M, Soto-Hernández AL, Milla-Kegel J, et al. Update of the Depression Scale of the Center for Epidemiologic Studies (CES-D). Pilot study in a Mexican geriatric sample [in Spanish]. Salud Ment. 2003;26:59-68.

24. Ostrosky F, López-Arango G, Ardila A Sensitivity and specificity of the MiniMental State Examination in a Spanishspeaking population. Appl Neuropsychol. 2000;7:25-31

25. American College of Sports Medicine. ACSM's Guidelines for Exercise Testing and Prescription. 8th ed. Philadelphia, Pa: Lippincott Williams \& Wilkins; 2009.

26. Hiyama Y, Yamada M, Kitagawa A, et al. A four-week walking exercise programme in patients with knee osteoarthritis improves the ability of dual-task performance: a randomized controlled trial. Clin Rehabil. 2011;26:403-412.

27. Silsupadol P, Shumway-Cook A, Lugade V, et al. Effects of single-task versus dual task training on balance performance in older adults: a double blind, randomized controlled trial. Arch Phys Med Rehabil. 2009;90:381-387.

28. Pichierri G, Murer K, de Bruin ED. A cognitive-motor intervention using a dance video game to enhance foot placement accuracy and gait under dual conditions in older adults: a randomized controlled trial. BMC Geriatr. 2012;12:74.

29. Sherder E, Eggermont L, Swaab D, et al. Gait in ageing and associated dementias: its relationship with cognition. Neurosci Biobehav Rev. 2007;31:485-497.

30. Allali G, Van der Meulen M, Assal F. Gait and cognition: the impact of executive function. Swiss Arch Neurol Psychiat. 2010; 161:195-199 